\title{
Socioeconomic disparities in health care use: Does universal coverage reduce inequalities in health?
}

\section{P J Veugelers, A M Yip}

See end of article for authors' affiliations

Correspondence to Dr P J Veugelers,

Department of Community Health and Epidemiology Faculty of Medicine,

Dalhousie University, 5849 University Avenue, Halifax, Nova Scotia, Canada B3H 4H7;

paul.veugelers@dal.ca

Accepted for publication 8 September 2002
Background: Despite enormous public sector expenditures, the effectiveness of universal coverage for health care in reducing socioeconomic disparities in health has received little attention.

Study objectives: To evaluate whether universal coverage for health care reduces socioeconomic disparities in health.

Design: Information on participants of the 1990 Nova Scotia Nutrition Survey was linked with eight years of administrative health services data and mortality. The authors first examined whether lower socioeconomic groups use more health services, as would be expected given their poorer health status. They then investigated to what extent differential use of health services modifies socioeconomic disparities in mortality. Finally, the authors evaluated health services use in the last years of life when health is poor regardless of a person's socioeconomic background.

Setting: The Canadian province of Nova Scotia, which provides universal health care coverage to all residents.

Participants: 1816 non-institutionalised adults, aged 18-75 years, from a two stage cluster sample stratified by age, gender, and region.

Main results: People with lower socioeconomic background used comparatively more family physician and hospital services, in such a way as to ameliorate the socioeconomic differences in mortality. In contrast, specialist services were comparatively underused by people in lower socioeconomic groups. In the last three years of life, use of specialist services was significantly higher in the highest income group.

Conclusions: Universal coverage of family physician and hospital services ameliorate the socioeconomic differences in mortality. However, specialist services are underused in lower socioeconomic groups, bearing the potential to widen the socioeconomic gap in health.
A socioeconomic gradient in health, whereby wealthier, more highly educated persons experience better health than poorer, less educated persons, has been well documented across and within many countries. Various mechanisms for this socioeconomic gradient in health have been proposed..$^{1-5}$ Poor lifestyle habits such as smoking, poor diet, and physical inactivity are more prevalent in lower socioeconomic groups. ${ }^{26-8}$ Similarly, the propensity to use preventive health services, such as regular medical check ups and participation in population screening programmes, is more prevalent among higher socioeconomic groups. ${ }^{167}$ In addition, financial and other barriers to health services may perpetuate or further augment existing socioeconomic disparities in health. ${ }^{59}$ The inability of lower socioeconomic groups to purchase costly health services or insurance may prevent them from accessing care. This poses an important disadvantage for these groups, given their greater burden of disease and corresponding greater need for health services. ${ }^{10-15}$

Publicly funded health care aims to deliver services on the basis of need rather than ability to pay, thus overcoming financial barriers to access and reducing inequity. Most developed countries provide some coverage of basic health services for segments of their populations. The extent and comprehensiveness of coverage, however, vary substantially among countries. ${ }^{16}$ In Canada, public health insurance evolved over the second half of the 20th century such that by the early 1970s, all provinces and territories provided universal coverage for hospital and physician services. In the context of an aging population and ever increasing health spending ${ }^{17}$ total public sector health expenditures for all the Canadian provinces and territories combined were estimated to reach $\$ 74465$ billion (53.68 billion euros) in 2001 , about $9.3 \%$ of gross domestic product ${ }^{18}$ - it is important to evaluate whether this financial burden indeed results in a reduction in socioeconomic health inequalities. The existing literature in this area generally consists of studies comparing the situation before and after the introduction of a universal health insurance programme. The US introduction of Medicare and Medicaid for certain segments of the population demonstrated that the resulting improved access to care substantially reduced disparities in health care utilisation ${ }^{6}$; however, gaps in coverage and in overall health status remain. ${ }^{19} 20$ Similarly, despite the introduction of the National Health Service in the UK, socioeconomic gradients in health and mortality have persisted.$^{21}{ }^{22}$ In Canada, a 1991 review of research covering the first two decades of Medicare concluded that the introduction of national health insurance had succeeded in providing a common entry point to the system by removing the basic barrier of out of pocket payment; however, socioeconomic disparities in the amount and type of care utilised and ultimately in health status remained. ${ }^{12}$ More recent evaluations are no longer based on comparisons with the situation before the introduction of Medicare and, instead, have often used the US as a comparison group. For example, comparisons of physician and hospital use in the Canadian province of Ontario and the US have suggested that Canada's single payer system has been successful in redistributing services to those with the most need, namely lower income people. ${ }^{13}{ }^{14}$ Also, comparisons of cancer survival in Canadian and US cities found that Canadians fared better, especially in lower socioeconomic groups. ${ }^{23-25}$ Canada and the US differ in numerous ways, ${ }^{5026}$ and thus the observed differences in health cannot solely be attributed to the differences in health care coverage. Additional studies are needed to investigate the 
Table 1 Characteristics of participants of the Nova Scotia Nutrition Survey

\begin{tabular}{|c|c|c|c|c|c|}
\hline Characteristic & $\begin{array}{l}\text { Included } \\
(n=1816)\end{array}$ & $\begin{array}{l}\text { Excluded (no } \\
\text { linkable } \\
\text { identifiers) } \\
(\mathrm{n}=82)\end{array}$ & p value* & $\begin{array}{l}\text { Excluded (income } \\
\text { missing) }(n=300)\end{array}$ & $\mathrm{p}$ valuet \\
\hline Mean age in years (SD) & $49.2(15.3)$ & $34.8(15.5)$ & $<0.01$ & $50.5(17.4)$ & 0.25 \\
\hline \multicolumn{6}{|l|}{$\operatorname{Sex}(\%)$} \\
\hline Female & $909(50.1)$ & $44(53.7)$ & \multirow[t]{2}{*}{0.52} & $186(62.0)$ & \multirow[t]{2}{*}{$<0.01$} \\
\hline Male & $907(49.9)$ & $38(46.3)$ & & $114(38.0)$ & \\
\hline Smoker $(\%)$ & $571(31.4)$ & $26(31.7)$ & 0.96 & $77(25.7)$ & 0.04 \\
\hline \multicolumn{6}{|l|}{ Body mass index (\%) } \\
\hline$<20$ & $83(4.6)$ & $10(12.2)$ & \multirow[t]{3}{*}{$<0.01$} & $15(5.0)$ & \multirow[t]{3}{*}{0.18} \\
\hline 20 to $<27$ & 903 (49.7) & $52(63.4)$ & & $132(44.0)$ & \\
\hline$\geqslant 27$ & $830(45.7)$ & $20(24.4)$ & & $153(51.0)$ & \\
\hline Diabetic (\%) & $148(8.2)$ & $1(1.2)$ & $0.02 \ddagger$ & $32(10.7)$ & 0.15 \\
\hline \multicolumn{6}{|l|}{ Household income (\%) } \\
\hline$<\$ 20000$ & $571(31.4)$ & $18(22.0)$ & & & \\
\hline$\$ 20000$ to $<\$ 40000$ & 713 (39.3) & $24(29.3)$ & & & \\
\hline$\geqslant \$ 40000$ & $532(29.3)$ & $28(34.2)$ & & & \\
\hline Missing & & $12(14.6)$ & & 300 (100.0) & \\
\hline \multicolumn{6}{|l|}{ Education (\%) } \\
\hline Less than high school & $786(43.3)$ & $23(28.1)$ & \multirow[t]{3}{*}{$<0.01$} & $157(52.3)$ & \multirow[t]{3}{*}{$<0.01$} \\
\hline High school, trade/vocational training & $526(29.0)$ & $19(23.2)$ & & $81(27.0)$ & \\
\hline College/university & $504(27.8)$ & $40(48.8)$ & & $62(20.7)$ & \\
\hline \multicolumn{6}{|l|}{ Family physician services } \\
\hline Median annual services (IQ range) & $4.75(6.38)$ & - & & $5.07(5.25)$ & 0.19 \\
\hline \multicolumn{6}{|l|}{ Specialist physician services } \\
\hline Median annual services (IQ range) & $1.25(3.50)$ & - & & $1.25(3.63)$ & 0.99 \\
\hline Hospital services - any use (\%) & $1146(63.1)$ & - & & 178 (59.3) & 0.21 \\
\hline Deaths (\%) & $149(8.2)$ & - & & $31(10.3)$ & 0.22 \\
\hline
\end{tabular}

adequacy of universal coverage in reducing socioeconomic disparities.

In this study, we use three approaches to evaluate whether universal coverage for health care reduces socioeconomic disparities in health. Firstly, we evaluate whether lower socioeconomic groups use more health services, as would be expected given their poorer health status. However, even if their use of health services is higher, this may still be inadequate to meet their greater needs and may potentially contribute to further inequalities in health. Therefore, in our second approach we evaluate to what extent the use of health services affects socioeconomic disparities in mortality. In the last years of life, health is poor and health care use is heavy, regardless of a person's socioeconomic background. In the absence of barriers to health care, it would be assumed that the demand for health services is similar across socioeconomic groups. As a third approach, we examine differential health care use by socioeconomic status in the last years of life.

\section{METHODS}

\section{Study design and health measures}

This study used data on participants of the Nova Scotia Nutrition Survey, linked with information on subsequent use of health services and vital statistics. ${ }^{5}{ }^{27}$ The survey was held in 1990 and consisted of 2198 non-institutionalised residents of the Canadian province of Nova Scotia, aged 18-75 years, from a two stage cluster sample stratified by age, gender, and region. Survey information of 82 participants (3.8\%) could not be linked with provincial health care databases and vital statistics and thus were not included in the analyses. The remaining 2116 survey participants were categorised into socioeconomic strata on the basis of their household income (less than \$20 000; \$20 000 to \$39 999; and \$40 000 or more). As the question on income was elective, this information was not available for 300 participants (13.6\%). Analyses were therefore restricted to the remaining 1816 participants. Information on health care use included the number of family physician services, specialist services, and days in hospital during the eight years afer the interview. During these eight years, $79(4.4 \%)$ participants migrated out of Nova Scotia while $149(8.2 \%)$ died; their observations, until the date of departure or death, were included in the analyses. The database linkages used in this study were approved by the Health Sciences Human Research Ethics Board of Dalhousie University, Halifax, Nova Scotia, Canada.

\section{Analytical approaches}

We compared characteristics and health outcomes of survey participants that were included and excluded from the present analyses using $\chi^{2}$, median, and $t$ tests.

We evaluated whether public health care reduces socioeconomic disparities in health in three different ways. Firstly, we described health care use (family physician services, specialist services, and days in hospital) for each of the socioeconomic strata during the eight years of follow up. As the distributions of health services use are highly skewed, we calculated the median number of health services in each stratum. In addition, we dichotomised health services use into low and heavy categories, using the median as a cut off, and calculated age and gender adjusted odds ratios of low compared with heavy health services use across socioeconomic strata using logistic regression.

Secondly, we evaluated the interrelations between health services use, socioeconomic background, and mortality during the eight years of study. We quantified socioeconomic differences in mortality in terms of age adjusted and gender adjusted odds ratios using logistic regression. When these odds ratios are further adjusted for health services use, the new odds ratios will be closer to unity if health services are used comparatively more by people of lower socioeconomic background and with comparatively poor health. In contrast, the adjustment for health services use will result in diverging odds ratios if people of lower socioeconomic background and with poor health use comparatively fewer health services. We present age and gender adjusted odds ratios for mortality by income category and odds ratios further adjusted for use of family physician and specialist services and days in hospital. 
Table 2 Differences in health services use by income among participants of the Nova Scotia Nutrition Survey

\begin{tabular}{|c|c|c|c|c|c|c|c|c|c|}
\hline \multirow[b]{2}{*}{ Income } & \multicolumn{3}{|c|}{ Family physician services } & \multicolumn{3}{|c|}{ Specialist services } & \multicolumn{3}{|c|}{ Days in hospital } \\
\hline & $\mathrm{N}$ & OR & $95 \% \mathrm{Cl}$ & $\mathrm{N}$ & OR & $95 \% \mathrm{Cl}$ & $\mathrm{N}$ & OR & $95 \% \mathrm{Cl}$ \\
\hline$<\$ 20000$ & 6.88 & reference & & 1.88 & reference & & 0.75 & reference & \\
\hline$\$ 20000-\$ 40000$ & 4.38 & 0.65 & 0.52 to 0.83 & 1.25 & 1.02 & 0.81 to 1.30 & 0.00 & 0.62 & 0.49 to 0.79 \\
\hline$>\$ 40000$ & 3.75 & 0.51 & 0.39 to 0.66 & 1.00 & 0.96 & 0.74 to 1.25 & 0.00 & 0.58 & 0.45 to 0.75 \\
\hline
\end{tabular}

$\mathrm{N}$, Median annual number of family physician services, specialist services, or days of hospitalisation; OR, odds ratio adjusted for age and gender differences; $95 \% \mathrm{Cl}, 95 \%$ confidence intervals of odds ratio.

Study participants

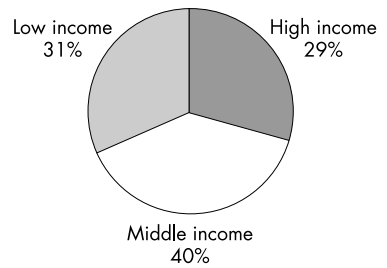

Specialist services
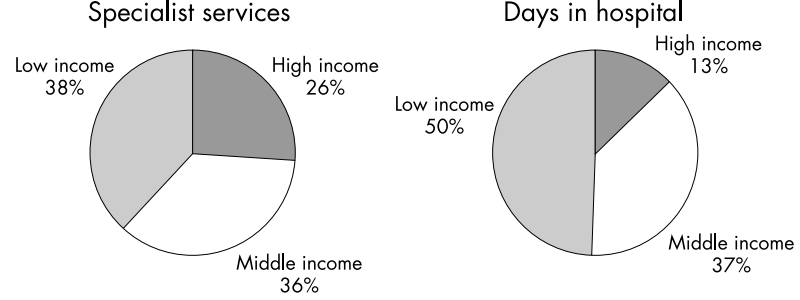

Figure 1 Distribution of study participants and health services use by income.

In a third analytical approach, we investigated health services use in the last years of life assuming that health in these years is poor regardless of socioeconomic background. For those who died during follow up, we described health services use (family physician services, specialist services, and days in hospital) during the three years preceding death for each of the socioeconomic strata. Here we also dealt with skewed distributions by using median values and calculating odds ratios that characterised the socioeconomic variation in low (below median) and heavy (above median) health services use.

We followed published guidelines ${ }^{28}$ for the longitudinal analysis of surveys with stratified sampling, which recommend adjusting for all variables used in defining sample weights (age, sex, and region), without incorporating these weights. As region did not substantially affect our estimates of interest, we retained only age and sex as covariates. Data were analysed using S-PLUS 2000 software.

\section{RESULTS}

Table 1 presents the characteristics and health outcomes of the 1816 participants with complete information in comparison with the $82(3.8 \%)$ that were excluded because of missing linkable identifiers, and with the $300(13.6 \%)$ that were excluded because of missing information on household income. The 82 for whom data linkage could not be established were substantially younger and from a higher income and better educated background. This clearly represents a young prosperous subgroup including students whose high mobility hampered linkages. The 300 with missing information on income were more likely to be female, nonsmokers, and less educated, but did not substantially differ from included participants with respect to health services use.

Figure 1 provides an initial visualisation of the distribution of health services use by income group. Participants who reported a household income of less than $\$ 20000$ constituted $31 \%$ of the study population and used disproportionately more health services; of all services delivered to this study population, the low income group used $43 \%$ of the family physician services, $38 \%$ of the specialist services, and $50 \%$ of the days in hospital. Participants with a household income of more than $\$ 40000$ constituted $29 \%$ of the study population and used $21 \%$ of the family physician services, $26 \%$ of the specialist services, and $13 \%$ of the days in hospital. This figure should be interpreted with caution, as differences are not controlled for the effects of age and gender. Table 2 presents the age and gender adjusted odds ratios for health services use by income group. Participants with an income of more than $\$ 40000$ were about half as likely (odds ratio $=0.51$ ) to be heavy users of family physician services than those with an income of less than $\$ 20000$. These differences were statistically significant. Variation in specialist services use across income groups was substantially less; all income groups had comparatively even distributions of heavy versus low users. With respect to hospital use, figures similar to those for family physician use were obtained; participants with higher income had fewer days in hospital than those in the lower income groups. These differences were also statistically significant.

Table 3 shows the differences in mortality by income group. The odds ratios adjusted for age and gender indicate lower mortality with increasing income (odds ratios of 0.79 and 0.56 for middle and high income groups respectively). These differences were attenuated by accounting for level of family physician services used (odds ratios of 0.90 and 0.68). Although the differences are not statistically significant, the attenuation suggests that family physician services were used more heavily by individuals with lower income and poorer health. Based on the premise that health services benefit

\begin{tabular}{|c|c|c|c|c|c|c|c|c|c|}
\hline \multirow[b]{2}{*}{ Income } & \multirow{2}{*}{$\begin{array}{l}\text { Deaths/ } \\
\text { participants }\end{array}$} & \multirow[b]{2}{*}{ OR } & \multirow[b]{2}{*}{$95 \% \mathrm{Cl}$} & \multicolumn{2}{|c|}{ Family physician services } & \multicolumn{2}{|c|}{ Specialist services } & \multicolumn{2}{|c|}{ Days in hospital } \\
\hline & & & & OR & $95 \% \mathrm{Cl}$ & OR & $95 \% \mathrm{Cl}$ & OR & $95 \% \mathrm{Cl}$ \\
\hline$<\$ 20000$ & $85 / 571$ & reference & & reference & & reference & & reference & \\
\hline$\$ 20000-\$ 40000$ & $47 / 713$ & 0.79 & 0.52 to 1.19 & 0.90 & 0.58 to 1.41 & 0.70 & 0.45 to 1.10 & 0.82 & 0.50 to 1.34 \\
\hline$>\$ 40000$ & $17 / 532$ & 0.56 & 0.31 to 1.02 & 0.68 & 0.36 to 1.26 & 0.33 & 0.17 to 0.66 & 0.66 & 0.34 to 1.27 \\
\hline
\end{tabular}

OR, odds ratio are all adjusted for age and gender differences and, in the corresponding columns, further adjusted for family physician services, specialist services, or days in hospital; $95 \% \mathrm{Cl}, 95 \%$ confidence intervals. 
Table 4 Differences in health services use in the three years before death among participants of the Nova Scotia Nutrition Survey

\begin{tabular}{|c|c|c|c|c|c|c|c|c|c|}
\hline \multirow[b]{2}{*}{ Income } & \multicolumn{3}{|c|}{ Family physician services } & \multicolumn{3}{|c|}{ Specialist services } & \multicolumn{3}{|c|}{ Days in hospital } \\
\hline & $\mathrm{N}$ & OR & $95 \% \mathrm{Cl}$ & $\mathrm{N}$ & OR & $95 \% \mathrm{Cl}$ & $N$ & OR & $95 \% \mathrm{Cl}$ \\
\hline$<\$ 20000$ & 13.57 & reference & & 5.90 & reference & & 7.76 & reference & \\
\hline$\$ 20000-\$ 40000$ & 16.64 & 1.12 & 0.54 to 2.31 & 7.18 & 1.07 & 0.52 to 2.22 & 12.44 & 1.20 & 0.58 to 2.49 \\
\hline$>\$ 40000$ & 15.38 & 0.36 & 0.11 to 1.14 & 20.10 & 4.67 & 1.35 to 16.22 & 11.83 & 1.27 & 0.43 to 2.00 \\
\hline
\end{tabular}

$\mathrm{N}$, Median number of annual family physician services, specialist services or days of hospitalisation; OR, odds ratio adjusted for age and gender differences; $95 \% \mathrm{Cl}, 95 \%$ confidence intervals of odds ratio.

\section{Key points}

- Universal coverage of family physician and hospital services ameliorates the socioeconomic differences in mortality.

- Despite universal coverage of specialist services, these services are underused in lower socioeconomic groups, bearing the potential to widen the socioeconomic gap in health.

health, these figures also indicate that family physician services reduced income disparities in mortality. Adjusting for specialist services use (odds ratios of 0.70 and 0.33) augmented the variation in mortality, indicating that specialist care did not contribute to a reduction in socioeconomic disparities. Accounting for days in hospital had an attenuating effect on income differences in mortality (odds ratios of 0.82 and 0.66 ) similar to the effect of family physician services.

Table 4 presents results of analyses similar to table 2 but only for the 149 participants who died during follow up. As would be expected, the level of health services use was much higher in the last years of life than in the general population (comparing median values presented in table 4 versus table 2 ). There was some variation in level of family physician services and hospital days used by income group, although not statistically significant. In contrast, specialist services use in the last years of life was significantly higher in the highest income group.

\section{DISCUSSION}

Lower socioeconomic groups experience poorer health status and have higher health care needs. This study shows that people with lower socioeconomic background and with poor health used comparatively more family physician and hospital services and in such a way as to ameliorate the socioeconomic differences in mortality. In contrast, specialist services were comparatively less used by people with lower socioeconomic background and with poor health; this underuse bears the potential to widen the socioeconomic gap in health.

Ecological comparisons of neighbourhoods within the Canadian cities of Winnipeg and Toronto demonstrated greater use of health services in lower income neighbourhoods relative to more affluent neighbourhoods. ${ }^{29} 30$ Similar trends were observed among people participating in the Canadian National Population Health Survey ${ }^{31}$ and in this study. Clearly, the poorer health of lower socioeconomic groups drives their increased use of health services, and universal coverage allows this to happen. To investigate whether this increased use of health services in lower socioeconomic groups is sufficient to meet their greater needs, researchers have quantified health services use while adjusting for socioeconomic differences in health care needs. In this respect, they have used self rated health and self reported health problems as proxies for health care need. Using such proxies, Dunlop et $a^{32}$ found that people of lower socioeconomic background consulted their family physician more frequently even if their higher needs for health

\section{Policy implications}

- Universal coverage of health care can be an effective means to reduce socioeconomic disparities in health.

- Identification of underused specialist services is important to facilitate health policy and targeted interventions aimed at further reduction of socioeconomic disparities in health.

services were controlled for. Specialist services, in contrast, were more frequently reported in higher income groups. ${ }^{32}$ With respect to hospital care, Newbold et $a l^{33}$ found no statistical differences among socioeconomic groups when differences in need for health services were controlled for. These findings are in agreement with our observations of health services use in the last three years of life, during which we assumed that need for health services was high regardless of a person's socioeconomic background. The studies by Dunlop et al and Newbold et al used self reported health services use based on national cross sectional surveys, whereas we conducted longitudinal analysis based on eight years of administrative health services data within the province of Nova Scotia. Also, the referenced studies considered need for health services use that was proxied by self rated health and self reported health problems, whereas we considered mortality during the eight years of follow up as a health outcome. The differing designs and populations of the above studies strengthen the mutual concern that specialist services do not equitably reach lower socioeconomic groups despite the existence of universal coverage. Furthermore, this study adds to the above findings by demonstrating that differential use of specialist services bears the potential to widen the socioeconomic gap in health, whereas family physician and hospital services are demonstrated to ameliorate the socioeconomic differences in mortality.

The increased use of family physician and hospital services in lower socioeconomic groups seems to correspond to their higher need resulting from their poorer health. This mechanism may contribute to the attenuation of the socioeconomic gradient in health. An example; hypertension is more prevalent in lower socioeconomic groups (A M Yip, et al, XVI IEA World Congress of Epidemiology, Montreal, QC, 18-22 August 2002). Family physician practice to control hypertension will reduce the cardiovascular risk burden that will particularly benefit the health of lower socioeconomic groups, thus contributing to the amelioration of the socioeconomic gradient in health. This study also showed that specialist services were comparatively less used in lower socioeconomic groups, while their need is again expected to be higher. This lower use of specialist services may be a result of differential referral to specialist services, as reported previously. ${ }^{79} 3234$

The high location rate $(75 \%)$ and response rate $(79 \%)$ of the Nova Scotia Nutrition Survey should be considered as an additional strength of this study. However, the exclusion of $3.8 \%$ of participants without linkable identifiers and 13.6\% without income information should be acknowledged as a limitation affecting the generalisability of the present results. 
Despite the exclusion of these participants, the sample size of 1816 participants seemed effective to reveal statistically significant associations between income groups with respect to health services (table 2). However, the sample size was insufficient to reveal statistically significant income differences in mortality and the extent to which income differences change when considering health services (table 3). This limitation urges confirmation of these findings by research in countries that provide universal coverage to their residents. Also, contrasting findings in countries with and without universal coverage are indicative of their effectiveness in socioeconomic disparities in health.

In conclusion, the expenditures for health care are enormous and likely to increase further in light of the aging population in most developed countries. The effectiveness of these expenditures in reducing socioeconomic health disparities has received comparatively little attention. As health care coverage is universal and hence the assessment of effectiveness is hampered by the absence of a comparison group, our understanding to date comes primarily from comparisons of the situation before and after the introduction of universal coverage and from comparisons of countries with and without universal coverage. As these comparisons all have limitations, the importance of new approaches to demonstrate effectiveness, such as this study, become apparent. These findings add new knowledge in that universal coverage of family physician and hospital services ameliorates the socioeconomic mortality differential. Specialist services, however, seem to be underused by lower socioeconomic groups and may contribute to widening this socioeconomic gap. Further research into the mechanisms and types of specialist services involved is important to facilitate health policy and targeted interventions aimed at further reduction of socioeconomic disparities in health.

\section{ACKNOWLEDGEMENTS}

The authors thank Angela Fitzgerald, Shane Hornibrook, George Kephart, Michael Pennock, Chris Skedgel, and Mark Smith for their helpful assistance. Parts of this research were presented at the Congress of Epidemiology 2001, Toronto, Canada, 13-16 June 2001.

\section{Authors' affiliations \\ P J Veugelers, A M Yip, Department of Community Health and Epidemiology, Faculty of Medicine, Dalhousie University, Halifax,} Canada

Funding: support for this study is provided through funding by the Canada Foundation for Innovation, the Dalhousie Medical Research Foundation, the Nova Scotia Health Research Foundation and a Canadian Institutes of Health Research Career Award to Dr Veugelers.

Conflicts of interest: none.

\section{REFERENCES}

1 Black D, Morris JN, Smith C, et al. The Black Report. In: Townsend P, Davidson N, Whitehead M, eds. Inequalities in health. London: Penguin, 1988:29-213.

2 Hertzman C, Frank J, Evans RG. Heterogeneities in Health Status and the Determinants of Population Health. In: Evans RG, Barer ML, Marmor TR, eds. Why are some people healthy and others not? The determinants of health of populations. New York: Aldine de Gruyter, 1994:67-92.

3 Veugelers PJ, Guernsey JR. Health deficiencies in Cape Breton County, Nova Scotia, Canada, 1950-1995. Epidemiology 1999:10:495-9.

4 Veugelers PJ, Yip AM, Mo D. The north-south gradient in health: analytic applications for public health. Can J Public Health 2001;92:95-8

5 Veugelers PJ, Yip AM, Kephart G. Proximate and contextual socioeconomic determinants of mortality: multilevel approaches in a setting with universal health care coverage. Am J Epidemiol $2001 ; 154: 725-32$
6 Davis K, Gold M, Makuc D. Access to health care for the poor: Does the gap remain? Ann Rev Public Health 1981;2:159-82.

7 Whitehead $M$. The health divide. In: Townsend P, Davidson N, Whitehead $M$, eds. Inequalities in health. London: Penguin, 1988:215-381

8 Lynch JW, Kaplan GA, Salonen JT. Why do poor people behave poorly? Variation in adult health behaviours and psychosocial characteristics by stages of the socioeconomic lifecourse. Soc Sci Med 1997:44:809-19.

9 Yip AM, Kephart G, Veugelers PJ. Individual and neighbourhood socioeconomic determinants of health care utilization: implications for health policy and resource allocation. Can J Public Health 2002:93:303-7.

10 Broyles RW, Manga P, Binder DA, et al. The use of physician services under a national health insurance scheme: an examination of the Canada Health Survey. Med Care 1983;21:1037-54.

11 Manga P, Broyles RW, Angus DE. The determinants of hospital utilization under a universal public insurance program in Canada. Med Care 1987;25:658-70

12 Badgley RF. Social and economic disparities under Canadian health care. Int J Health Serv 1991:21:659-71.

13 Katz SJ, Hofer TP, Manning WG. Physician use in Ontario and the United States: the impact of socioeconomic status and health status. Am J Public Health 1996;86:520-4

14 Katz SJ, Hofer TP, Manning WG. Hospital utilization in Ontario and the United States: the impact of socioeconomic status and health status. Can J Public Health 1996;87:253-6.

15 Andrulis DP. Access to care is the centerpiece in the elimination of socioeconomic disparities in health. Ann Intern Med 1998;129:412-16.

16 The Standing Senate Committee on Social Affairs, Science and Technology. Interim Report on the state of the health care system in Canada. The health of Canadians-The Federal Role. Vol Three-Health care systems in other countries. Ottawa: January 2002.

17 Wolfe S. Ethics and equity in Canadian health care: policy alternatives. Int J Health Serv 1991;21:673-80.

18 Canadian Institute for Health Information. National health expenditure trends 1975 to 2001 . Ottawa: December 2001.

19 Evans R, Roos NP. What is right about the Canadian health care system? Milbank Q 1999;77:393-9.

20 Starfield B. Is US health really the best in the world? JAMA 2000;284:483-5.

21 Marmot MG, Kogevinas M, Elston MA. Social/economic status and disease. Ann Rev Public Health 1987;8:111-35.

22 Susser $\mathbf{M}$. Health as a human right: an epidemiologist's perspective on the public health. Am J Public Health 1993:83:418-26.

23 Gorey KM, Holowaty EJ, Fehringer G, et al. An international comparison of cancer survival: Toronto, Ontario, and Detroit, Michigan, metropolitan areas. Am J Public Health 1997;87: 1 156-63.

24 Gorey KM, Holowaty EJ, Fehringer G, et al. An international comparison of cancer survival: relatively poor areas of Toronto, Ontario and three US metropolitan areas. J Public Health Med 2000;22:343-8.

25 Gorey KM, Holowaty EJ, Fehringer $G$, et al. An international comparison of cancer survival: metropolitan Toronto, Ontario, and Honolulu, Hawaii. Am J Public Health 2000;90:1866-72.

26 Ross NA, Wolfson MC, Dunn JR, et al. Relation between income inequality and mortality in Canada and in the United States: cross sectional assessment using census data and vital statistics. BM 2000;320:898-902.

27 Kephart G, Thomas VS, MacLean DR. Socioeconomic differences in the use of physician services in Nova Scotia. Am J Public Health 1998;88:800-3.

28 Korn EL, Graubard BI. Epidemiologic studies utilizing surveys: Accounting for the sampling design. Am J Public Health 1991;81:1166-73.

29 Roos NP, Mustard CA. Variation in health and health care use by socioeconomic status in Winnipeg, Canada: does the system work well? Yes and no. Milbank Q 1997:75:89-111.

30 Glazier RH, Badley EM, Gilbert JE, et al. The nature of increased hospital use in poor neighbourhoods: findings from a Canadian inner city. Can J Public Health 2000;91:268-73.

31 Johansen H, Millar WJ. Health care services - recent trends. Health Rep 1999;11:91-109.

32 Dunlop S, Coyte PC, Mclsaac W. Socio-economic status and the utilisation of physicians' services: results from the Canadian National Population Health Survey. Soc Sci Med 2000;51:123-33.

33 Newbold KB, Eyles J, Birch S. Equity in health care: methodological contributions to the analysis of hospital utilization in Canada. Soc Sci Med 1995;40:1181-92.

34 Wiggers JH, Sanson-Fisher RW, Halpin SJ. Prevalence and frequency of health service use: associations with occupational prestige and educational attainment. Aust J Public Health 1995;19:512-19. 